\title{
BMJ Open Geographical variation of emergency hospital admissions for ambulatory care sensitive conditions in older adults in Ireland 2012-2016
}

\author{
Mary E Walsh (D) , ${ }^{1}$ Sinead Cronin, ${ }^{1}$ Fiona Boland (i) , ${ }^{1}$ Mark H Ebell (D) , ${ }^{2}$ \\ Tom Fahey (D) , ${ }^{1}$ Emma Wallace ${ }^{1}$
}

To cite: Walsh ME, Cronin S, Boland F, et al. Geographical variation of emergency hospital admissions for ambulatory care sensitive conditions in older adults in Ireland 2012-2016. BMJ Open 2021;11:e042779. doi:10.1136/ bmjopen-2020-042779

- Prepublication history and supplemental material for this paper is available online. To view these files, please visit the journal online (http://dx.doi org/10.1136/bmjopen-2020042779).

Received 14 July 2020 Revised 17 February 2021 Accepted 13 April 2021

A Check for updates

(c) Author(s) (or their employer(s)) 2021. Re-use permitted under CC BY-NC. No commercial re-use. See rights and permissions. Published by BMJ.

${ }^{1}$ HRB Centre for Primary Care Research, Department of General Practice, Royal College of Surgeons in Ireland, Dublin, Ireland

${ }^{2}$ Epidemiology and Biostatistics, University of Georgia, Athens, Georgia, USA

Correspondence to

Dr Emma Wallace;

emmawallace@rcsi.ie

\section{ABSTRACT}

Objective Ambulatory care sensitive (ACS) conditions are those for which intensified primary care management could potentially prevent emergency admissions.

This study aimed to quantify geographical variation in emergency admissions with ACS conditions in older adults and explore factors influencing variation.

Design Repeated cross-sectional study.

Setting 34 public hospitals in the Ireland.

Participants Adults aged $\geq 65$ years hospitalised for seven ACS conditions between 2012 and 2016 (chronic obstructive pulmonary disease, congestive heart failure (CHF), diabetes, angina, pyelonephritis/urinary tract infections (UTIS), dehydration and pneumonia).

Primary outcome measure Age and sex standardised emergency admission rates (SARs) per 1000 older adults. Analysis Age and sex SARs were calculated for 21 geographical areas. Extremal quotients and systematic components of variance (SCV) quantified variation. Spatial regression analyses was conducted for SARs with unemployment, urban population proportion, hospital turnover, supply of general practitioners (GPS), and supply of hospital-based specialists as explanatory variables. Results Over time, an increase in UTI/pyelonephritis SARs was seen while SARs for angina and CHF decreased. Geographic variation was moderate overall and high for dehydration and angina (SCV=11.7-50.0). For all conditions combined, multivariable analysis showed lower urban population (adjusted coefficient: $-2.2(-3.4$ to -0.9 , $\mathrm{p}<0.01)$ ), lower GP supply (adjusted coefficient: $-5.5(-8.2$ to $-2.9, p<0.01)$ ) and higher geriatrician supply (adjusted coefficient: 3.7 (0.5 to $6.9, p=0.02)$ ) were associated with higher SARs.

Conclusions Future research should evaluate methods of preventing admissions for ACS conditions among older adults, including how resources are allocated at a local level.

\section{INTRODUCTION}

Emergency hospital admission can place older adults at risk of functional decline, infection, delirium and pressure injuries. ${ }^{1}$ In Ireland, over half of older adults report at least one chronic illness and the majority of public hospital days are used by this cohort. ${ }^{23}$
Strengths and limitations of this study

- This study uses a large national dataset, which is known to have good coverage and accuracy across public hospitals.

- Definitions of conditions and methods of quantifying variation are in line with international work.

- Undifferentiated presentations in older, multimorbid patients could result in more diagnostic uncertainty and variation in clinical coding across areas

- Presentations to emergency departments that did not result in emergency admission due to lack of bed availability were not included in the analysis.

- Future research is required to explore the mechanisms of observed associations at an individual level to inform interventions to prevent ambulatory care sensitive admissions.

Approximately $20 \%$ of all emergency admissions are due to ambulatory care sensitive (ACS) conditions and considered potentially avoidable through chronic disease management interventions in the primary care setting and implementation of vaccination programmes that prevent acute illnesses including influenza. ${ }^{45}$ The National Health Service Institute for Innovation and Improvement (NHS Institute) in England highlights 19 ACS conditions. ${ }^{45}$ Some of these disproportionately affect older adults with over two-thirds of emergency hospital admissions for chronic obstructive pulmonary disease (COPD), pneumonia and urinary tract infections (UTIs) in England, and for COPD, diabetes complications and congestive heart failure (CHF) in Ireland affecting the over 65-year age group. ${ }^{4-6}$

Geographical variation of hospitalisations for these conditions has been studied in several countries in different patient populations with primary care supply/quality, secondary care access and patient deprivation 
being the most frequent drivers of hospitalisation..$^{7-9}$ These factors have not been explored among the older adult population in Ireland. It is important to identify system and population level factors that may be amenable to intervention in this setting. The aim of this study is to examine the extent of geographical variation in emergency hospital admissions for ACS conditions among older adults in Ireland. Secondary aims are to explore secular trends and the association of healthcare demand and supply factors with variation.

\section{METHODS}

The Strengthening the Reporting of Observational Studies in Epidemiology guidelines were used to guide the conduct and reporting of this repeated cross-sectional study. ${ }^{10}$

\section{Setting}

The Ireland had a population of 4.7 million people in 2016 , with $13.5 \%$ aged $\geq 65$ years. ${ }^{3}$ All residents are entitled to receive publicly funded hospital care. Additional schemes are available to residents aged $\geq 70$ years, those below certain income thresholds and those with particular chronic conditions to provide services at reduced or no 'out-of-pocket' cost including general practice visits and medications. ${ }^{11}$

\section{Participant selection}

For this study, tabulations (by year, residence area, sex and 5-year age group) of emergency hospital admissions with a discharge date between 1 January 2012 and 31 December 2016 and aged $\geq 65$ years were extracted from the national Hospital Inpatient Enquiry system (HIPE), the main dataset that includes all inpatient and day case admissions to publicly-funded acute hospitals in Ireland. ${ }^{2}$ Further details of HIPE, which has over 99\% coverage, are available in online supplemental table 1 . In line with previously published definitions, seven conditions that contribute to most potentially preventable emergency admissions in older adults in Ireland and internationally were chosen for analysis. ${ }^{612} 13$ These seven conditions are a subset of the ACS conditions identified by the NHS Institute, ${ }^{45}$ and are in line with conditions studied among older adults in the US as part of the Dartmouth Atlas of healthcare variation ${ }^{12}$ (see online supplemental table 2 for detailed definitions):

- COPD

- $\mathrm{CHF}$

- Diabetes complications

- Angina (excluding therapeutic procedures)

- Pyelonephritis and UTIs

- Dehydration

- Pneumonia

Emergency hospital admissions were excluded if they were $<65$ years, not resident in Ireland or were discharged directly from Acute Medical Admission Units (which can serve a similar purpose as Emergency Departments). ${ }^{2}$
Formal ethical approval was not sought, as the study was conducted using aggregated data from national anonymous administrative datasets (see online supplemental table 2 for a full list of exclusions).

\section{Definition of small areas and calculation of standardised admission rates}

Age-stratified and sex-stratified population counts for persons aged $\geq 65$ years in each of 26 counties in Ireland and the areas of North Dublin and South Dublin were obtained from 2011 and 2016 national censuses and counts for intercensus years were calculated assuming uniform annual growth rates. ${ }^{3}$ Small counties were grouped with neighbouring counties to produce more stable estimates, ${ }^{14}$ thus defining 21 small areas. For each condition, discharge rates per 1000 older residents were calculated by year for each small area. To aid international comparison, rates were indirectly age and sex standardised, using the United States 2015 population structure (www.census.gov).

\section{Secular trends}

For each condition, changes in rates over time were explored using linear regression analysis with annual Standardised Admission Rate (SAR) as the outcome. This was not conducted for diabetes complications as a coding change in 2015 reduces comparability of years for this condition. $^{15}$

\section{Quantifying variation}

The extent of variation for each condition across small areas was estimated using the extremal quotient $(\mathrm{EQ}$ maximum rate/minimum rate) and the systematic component of variation (SCV) ${ }^{16}{ }^{17}$ The SCV, representing nonrandom variation, is calculated by $\frac{1}{k}\left(\sum_{i=1}^{k} \frac{\left(O_{i}-E_{i}\right)^{2}}{E_{i}^{2}}-\sum_{i=1}^{k} \frac{1}{E_{i}}\right)$ where $\mathrm{k}$ is the number of small areas, $\mathrm{O}_{i}$ is the observed number of discharges in the ith small area, and $\mathrm{E}_{\mathrm{i}}$ is the expected number of discharges determined by direct standardisation. ${ }^{16}$ An SCV value $>5$ represents high variation and $>10$ is considered very high variation. ${ }^{16}$ These values were also calculated eliminating small areas outside the 5th-95th percentiles $\left(\mathrm{EQ}_{5-95}, \mathrm{SCV}_{5-95}\right) .{ }^{16} \mathrm{~A}$ standardised admission ratio (observed/expected number of admissions) was calculated for each condition, year and area. Maps of standardised admission ratios were generated using Stata V.14 (StataCorp, Texas, USA).

\section{Explaining variation}

For each condition and all conditions combined, univariable and multivariable regression analysis was conducted with average 5-year SAR as the outcome, and five arealevel explanatory variables related to healthcare supply and demand. These included unemployment rate (socioeconomic deprivation), urban population proportion (rurality), hospital turnover (proportion of emergency admissions with short lengths of stay) ${ }^{18}$ and the density of general practitioners (GPs) and relevant hospital-based 
Table 1 Demographic profile of emergency hospital admissions for ambulatory care sensitive conditions (2012-2016)

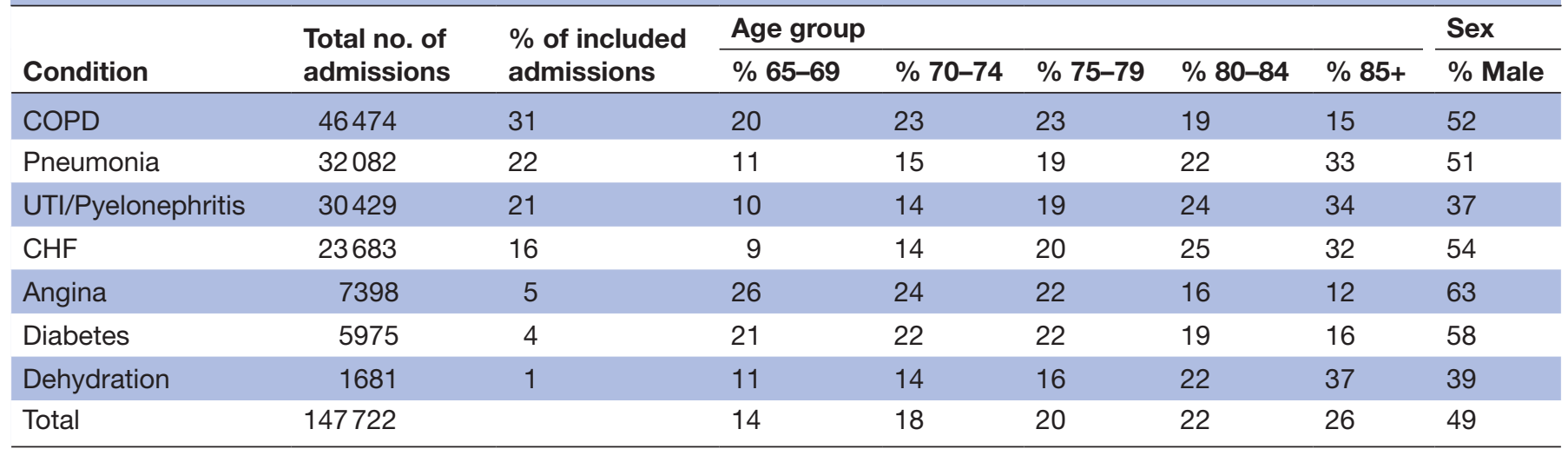

CHF, congestive heart failure; COPD, chronic obstructive pulmonary disease; UTI, urinary tract infection.

specialists (geriatricians, cardiologists, respiratory specialists and endocrinologists). See online supplemental table 3 for full definitions and summary values of each variable. A random effect to account for small-area clustering was included in models. Spatial diagnostic tests ('spatdiag' in Stata V.14) were conducted and proximal small-areas' influence on one another's results explored using Moran's I and Robust Lagrange multiplier values. If spatial relationships were found, spatial analysis, incorporating a 'contiguity matrix', was conducted. ${ }^{19}{ }^{20}$ Stata V.14 (StataCorp, Texas, USA) was used for all analyses.

\section{Patient and public involvement}

Patients were not involved in the conception, design, or conduct of this research.

\section{RESULTS}

\section{Demographics}

Between 1 January 2012 and 31 December 2016, a total of 147722 emergency hospital admissions (49\% men) due to seven ACS conditions in older adults were included. Table 1 presents demographics of included admissions. Approximately one-third of those admitted with $\mathrm{CHF}$, pneumonia, UTI/pyelonephritis and dehydration were aged $\geq 85$ years, while angina was most common in men and younger age groups.

\section{Secular trends}

Over time, no change was observed in SARs for all conditions combined or for individual conditions COPD, dehydration and pneumonia. A significant decrease in SARs for angina (coefficient: $-0.2(95 \%$ CI -0.3 to -0.1$))$ and CHF (coefficient: -0.2 (95\% CI -0.4 to -0.0$)$ ) was found with a significant increase in UTI/pyelonephritis admissions (coefficient: 0.7 (95\% CI 0.5 to 0.9$)$ ).

\section{Quantifying variation}

Table 2 shows geographic variation measures for ACS conditions. There was some variation observed for all conditions combined in most years, but high variation $(\mathrm{SCV}=5.3)$ was only observed in 2013. Based on SCV values, $\mathrm{CHF}$ admissions demonstrated low variation $(\mathrm{SCV}=2.4-3.5)$. COPD, diabetes complications, pyelonephritis/UTI and pneumonia admissions demonstrated high variation (SCV=4.1-14.4). Angina and dehydration admissions showed very high variation ( $\mathrm{SCV}=11.7-50.0)$. Crude rates, $\mathrm{EQ}_{5-95}$ and $\mathrm{SCV}_{5-95}$ values are detailed in online supplemental table 4.

Figure 1 shows the geographic distribution of Standardised Admission Ratios in 2016 across Ireland. Darker areas show higher than expected numbers of admissions while lighter areas show lower than expected numbers of admissions. Generally, a lower number of admissions than expected were seen in the south and in Dublin and a higher number of admissions than expected in the midlands areas. This distribution across all years (20122016) is presented in online supplemental figure S1.

\section{Explaining variation}

Spatial tests were significant for all conditions combined, diabetes, UTI/pyelonephritis, pneumonia and dehydration. In multivariable spatial analysis, higher SARs per 1000 older population for all seven ACS conditions combined were associated with a lower population proportion living in urban areas (adjusted coefficient: -2.2 (95\% CI -3.5 to $-0.9, \mathrm{p}<0.01)$; 10-point change), lower GP density per 10000 population (adjusted coefficient: -5.5 (95\% CI -8.2 to $-2.9, \mathrm{p}<0.01)$ ), and higher geriatrician density per 10000 older population (adjusted coefficient: $3.7(95 \%$ CI 0.5 to $6.9, \mathrm{p}=0.02)$ ).

When conditions were analysed individually, lower GP density was the most frequent factor associated with higher SARs including for COPD (adjusted coefficient: $-2.1(95 \% \mathrm{CI}-4.2$ to -0.1$), \mathrm{p}=0.05)$, CHF (adjusted coefficient: $-0.9(95 \%$ CI -1.6 to -0.3$), p=0.01)$, diabetes mellitus (adjusted coefficient: -0.3 (95\% CI -0.6 to -0.1 ), $\mathrm{p}=0.02$ ) and UTI/pyelonephritis (adjusted coefficient: $-1.1(95 \%$ CI -2.1 to -0.1$), \mathrm{p}=0.02)$. Higher area-level unemployment was associated with higher COPD SARs (adjusted coefficient: 0.9 (95\% CI 0.1 to 1.6$), \mathrm{p}=0.02$ ) and lower urban population was associated with higher UTI/pyelonephritis emergency admission rates (adjusted 
Table 2 Quantifying variation in ambulatory care sensitive emergency hospital admission rates in older adults

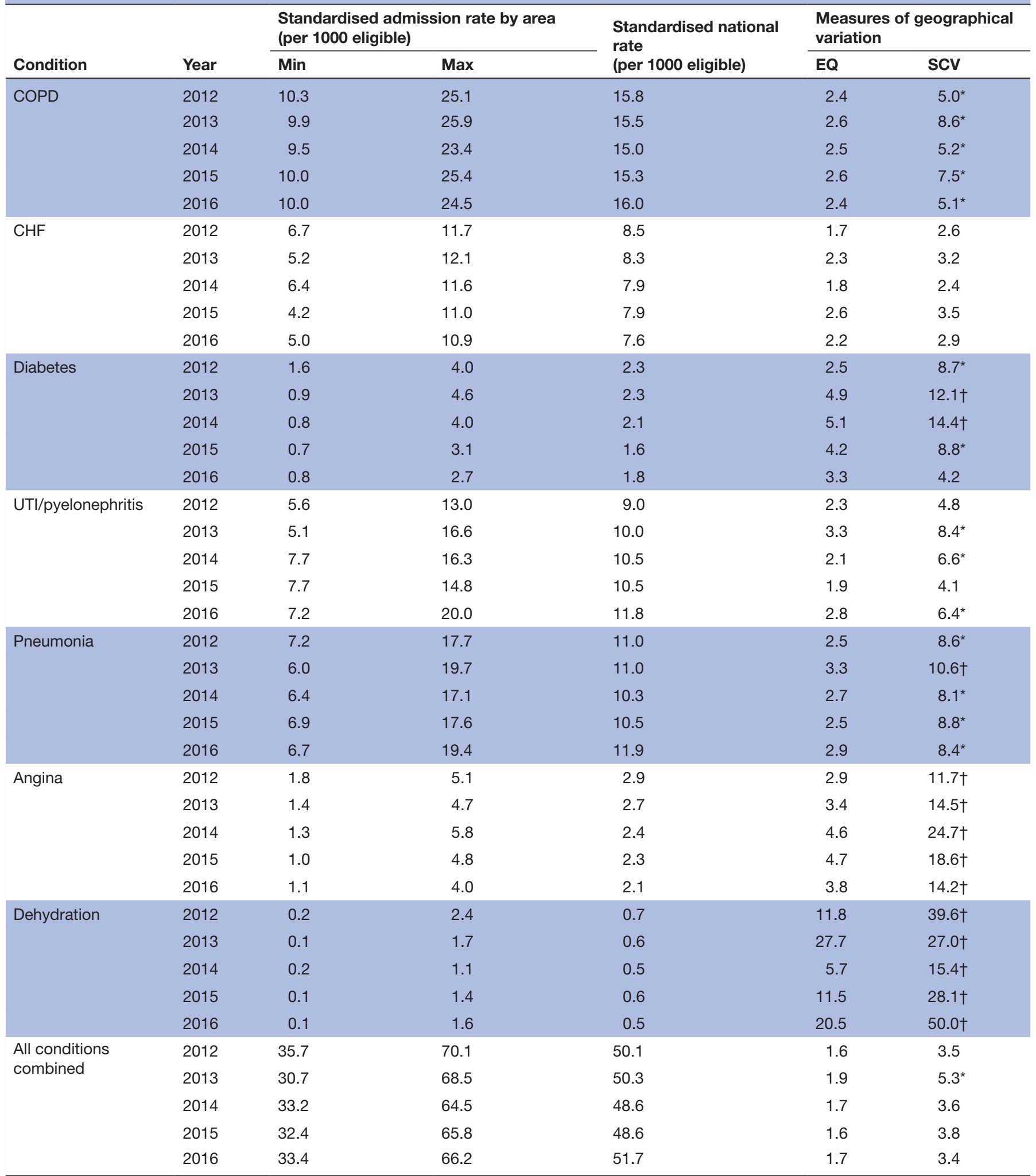

*High variation.

†Very high variation (systematic component of variation (SCV) >3 likely be to 'medical discretion'; 5-10=high variation; >10 very high variation). $\mathrm{CHF}$, congestive heart failure; COPD, chronic obstructive pulmonary disease; EQ, extremal quotient; UTI, urinary tract infection.

coefficient $-0.5(95 \%$ CI -1.0 to -0.1$)$, $\mathrm{p}=0.03)$. Hospital turnover was associated with higher SARs for dehydration (adjusted coefficient: 0.04 (95\% CI 0.01 to 0.07 ), $\mathrm{p}=0.02$ ). See online supplemental tables 5 and 6 for all coefficients.

\section{DISCUSSION}

Summary of principle findings

This study examined geographical variation in emergency hospital admissions for seven ACS conditions 


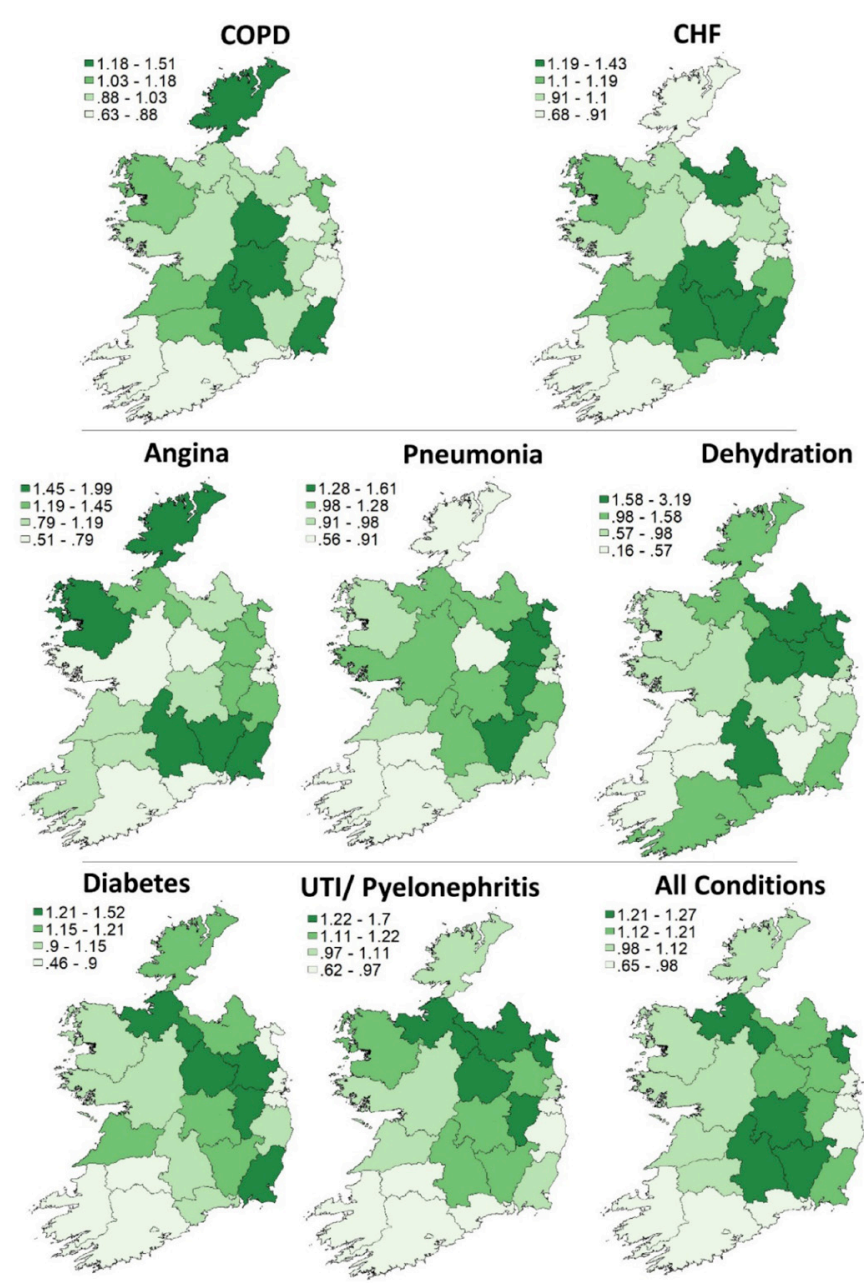

Figure 1 Geographical distribution of standardised admission ratios for ambulatory care sensitive conditions for the year 2016. CHF, congestive heart failure; COPD, chronic obstructive pulmonary disease; UTI, urinary tract infection.

among older adults in Ireland over a 5-year period (2012-2016). Emergency admission rates for all conditions studied varied across geographical areas from 1.6 to 1.9 fold, showing high variation only in the year 2013 . This is broadly in line with similar research internationally. ${ }^{7}$ While emergency admission for dehydration and angina demonstrated very high variation, SARs for these conditions were low ( $<3 / 1000$ population), which could account for the magnitude of variation observed as well as changes in measures of variation from year to year. ${ }^{16}$ For conditions with higher and comparable rates (COPD, CHF, UTI/pyelonephritis, pneumonia), pneumonia showed the highest variation (three-fold).

There were three main factors which showed evidence of associations with higher rates of emergency admissions for all conditions in the current study: (1) density of GPs, (2) rurality and (3) density of geriatricians.

\section{Findings in relation to other studies} GP supply

Lower density of GPs was associated with higher emergency admission rates for all seven ACS conditions combined as well as for CHF, diabetes and UTI/pyelonephritis. This is in line with international research among older adults, ${ }^{21}$ although studies among general populations have shown inconsistent associations between ACS admission rates and GP supply. ${ }^{7}$ A lack of GPs managing chronic conditions and implementing vaccination programmes in community settings could result in more patients attending emergency departments with acute exacerbations or complications of their chronic condition. ${ }^{5}$ It is also important to consider the value of continuity of care with the same GP, which we could not measure in this study, but which has been found to reduce emergency admissions among older adults. ${ }^{22}$

\section{Rurality}

In this study, rurality (lower urban population) was associated with higher rates of emergency admissions for all conditions combined as well as for UTI/pyelonephritis. This pattern has also been observed among older adults in the USA and broader populations in Europe. ${ }^{21} 23$ Ireland has a relatively low population density, with the majority concentrated in three large cities. Between 2005 and 2008 in Ireland, Sheridan et al reported that hospitalisation rates for acute and chronic ACS conditions were higher outside of these cities. ${ }^{6}$ Rural areas in Ireland are likely to have lower physician supply, and greater travel times to hospitals. ${ }^{9}$ This could also influence access to clinical decision-making support services including radiology and the availability of community support services, which could lower admission thresholds. ${ }^{8}$

\section{Geriatrician supply}

In this study, higher geriatrician density was associated with higher emergency admission rates on multivariable analysis. This relationship could be interpreted as indicating 'supply-sensitive' care. ${ }^{24}$ Greater numbers of geriatricians may result in more capacity to admit and investigate older patients in hospital. This may suggest some unmet need in areas with lower admission rates. It is not clear however if more and higher cost treatments results in better outcomes in this cohort. ${ }^{24}$ Counterintuitively, Wennberg in 2011 described how in the USA, areas with high expenditure for chronic conditions among older adults have higher rates of mortality. ${ }^{24}$ This may not translate to other countries and research is needed to determine higher value healthcare activity in terms of patient outcomes.

\section{Secular trends}

Rates of hospitalisation for angina and CHF decreased by $28 \%$ and $13 \%$ respectively over the period of the study. These findings are similar to observed trends among older adults in the USA from 2003 to 2007 and in the general population in England from 2002 to $2012^{413}$ One explanation of this decrease could be increased use of percutaneous coronary intervention, which rose by $36 \%$ between 2004 and 2011 in Ireland. ${ }^{25}$ With regards to CHF however, large epidemiological European studies suggest that while 
incidence and mortality are declining, total prevalence is rising with population ageing. ${ }^{2627}$ In our study, consistent with findings from England, most CHF admissions were in individuals aged $\geq 80$ years with relatively low variation seen nationally. ${ }^{4}$ This highlights a need to explore improved community-based management strategies for CHF among the oldest old and those approaching endof-life. SARs for UTI/pyelonephritis increased by $31 \%$ over the period of this study. Similar increases in UTI have been observed in national analyses among the older population in the USA and England. ${ }^{413} 28$ Simmering $e t$ al examined UTI admissions in the USA between 1998 and 2011 and reported an increase from 264404 (12.9 per 10000 people) to 436635 (18.4 per 10000 people). ${ }^{28}$ The majority of this increase in admissions occurred among women $(67.7 \%$ in $1998,71.4 \%$ in 2011$)$, with the mean age at admission increasing from 73.2 to 74.7 years. Mean length of hospital stay for UTI-related admissions decreased from 5.29 to 4.24 days and inpatients had a lower odds of death (68\% lower in 2011 than in 1998). The authors hypothesised that this increase in admissions was associated with difficulties treating UTIs in outpatient settings due to antimicrobial resistance, with the reduced length of inpatient stay and lower odds of death indicative of less severe infections requiring admission. ${ }^{28}$ This is a concerning trend that could have implications for healthcare costs and efficacy. It highlights the need to consider focused antibiotic stewardship efforts for patients diagnosed with UTIs, new oral or single-dose antimicrobial agents that can administered in outpatient settings, and innovative approaches to treat patients with UTI with resistant pathogens on an outpatient basis. ${ }^{28} 29$

\section{Strengths and weaknesses of the study}

This study was conducted using a large, national database representing all public hospitals in the Ireland; however, HIPE is not designed for research purposes. ${ }^{30}$ Limitations with and differences regarding clinical coding accuracy across hospital sites could account for some variation found. ${ }^{8}$ Undifferentiated presentations in older, multimorbid patients could result in more diagnostic uncertainty, particularly with regard to dehydration, a complex presentation for which other diagnoses may be implicated. Furthermore, exploring only hospitalisation rates does not give an indication of care quality. ${ }^{30}$ Given the study design and data available, there may be other factors influencing ACS admissions that we were unable to explore including illness severity, multimorbidity, social services and discharge transitions. ${ }^{8}$ Factors including deprivation were explored at a county-level, areas that may be too large to detect differences within communities.

Acute public hospitals in Ireland have an average bed occupancy of $95 \%$ throughout the year, which is significantly higher than the European average of $77 \% .{ }^{31}$ Long emergency department waiting times, a feature of Irish public hospitals, is a priority for the health service. ${ }^{32}$ As emergency department figures are not included in this analysis, it is possible that patients who required admission but for whom a bed never became available have not been accounted for. We attempted to account for the supply-sensitive factor of hospital turnover by incorporating the propensity of an area to have short emergency stays in hospital as it was found to be important in previous Irish work. ${ }^{18}$ This is a complicated variable however and may not fully reflect real-life circumstances. Patient reported access to general practice during routine and out of hours could not be accounted for. In a UK study, every percentage-point increase in patient reported inability to make a GP appointment was associated with an increase in emergency attendance by 0.36 (95\% CI 0.06 to 0.66 ) per 1000 population. Percentagepoint increases in patients unable to speak to a GP/nurse within two workdays and patients able to speak often to their preferred GP were associated with increased emergency attendance/ 1000 population by 0.23 (95\% CI 0.05 to 0.42 ) and 0.10 (95\% CI 0.00 to 0.19 ), respectively. ${ }^{33}$ Lastly, our data does not include admissions to private hospitals, which nationally make up a small proportion of these types of presentations.

\section{Implications for research and practice}

Our study found an association between ACSC emergency admission rates and health-system factors among older adults. However, this study design cannot explain causal mechanism, which is an area for future research. ${ }^{30}$ A patient's decision to attend for emergency care is determined by a complex network of personal, socioeconomic, cultural and health service factors. ${ }^{8}$ Future high quality research is required to explore this process and to evaluate models of preventability of exacerbations of chronic conditions and the potential avoidability of certain hospitalisations among older adults at a system level. ${ }^{8}$ Efforts to address ACS emergency admissions could focus on interventions in socio-economically disadvantaged areas with higher rates of ACS admissions, targeting certain ACS conditions, such as COPD, where there is evidence to support primary care interventions reducing admissions and consider interventions focused on reducing length of stay for patients admitted to hospital. ${ }^{34}$

\section{CONCLUSION}

In health system planning, services should be tailored to meet the needs of the population. This study provides important insights into factors that may influence inequity in care for older adults that leads to differences in hospitalisation rates; rurality, GP supply and geriatrician supply. In an ageing population with increasing levels of multimorbidity and complex care needs, primary healthcare is essential and needs to be adequately resourced. Future research is required to evaluate methods of preventing admissions for ACS conditions among older adults, including how resources are allocated at a local level. 
Contributors MEW, TF and EW conceptualised the study. FB and MEW analysed the data and MEW, SC, MHE, TF and EW interpreted the results. MEW and SC wrote the original draft and TF, MHE and EW contributed to the editing and reviewing of the paper. EW is the guarantor.

Funding Support was received from the Health Research Board (HRB) in Ireland through grant number $\mathrm{HRC} / 0014 / 1$ (TF).

Disclaimer The funders had no role in study design, data analysis, decision to publish, or preparation of the manuscript.

Map disclaimer The depiction of boundaries on the map(s) in this article does not imply the expression of any opinion whatsoever on the part of BMJ (or any member of its group) concerning the legal status of any country, territory, jurisdiction or area or of its authorities. The map(s) are provided without any warranty of any kind, either express or implied.

Competing interests None declared.

Patient consent for publication Not required.

Provenance and peer review Not commissioned; externally peer reviewed.

Data availability statement Data may be obtained from a third party and are not publicly available. Access to Hospital Inpatient Enquiry system data was requested and accessed through Health Intelligence Ireland, HSE. Census data is publically available from the Central Statistics Office at http://www.cso.ie/en/census/ interactivetables/.

Supplemental material This content has been supplied by the author(s). It has not been vetted by BMJ Publishing Group Limited (BMJ) and may not have been peer-reviewed. Any opinions or recommendations discussed are solely those of the author(s) and are not endorsed by BMJ. BMJ disclaims all liability and responsibility arising from any reliance placed on the content. Where the content includes any translated material, BMJ does not warrant the accuracy and reliability of the translations (including but not limited to local regulations, clinical guidelines, terminology, drug names and drug dosages), and is not responsible for any error and/or omissions arising from translation and adaptation or otherwise.

Open access This is an open access article distributed in accordance with the Creative Commons Attribution Non Commercial (CC BY-NC 4.0) license, which permits others to distribute, remix, adapt, build upon this work non-commercially, and license their derivative works on different terms, provided the original work is properly cited, appropriate credit is given, any changes made indicated, and the use is non-commercial. See: http://creativecommons.org/licenses/by-nc/4.0/.

\section{ORCID iDs}

Mary E Walsh http://orcid.org/0000-0001-8920-7419

Fiona Boland http://orcid.org/0000-0003-3228-0046

Mark H Ebell http://orcid.org/0000-0003-3228-2877

Tom Fahey http://orcid.org/0000-0002-5896-5783

\section{REFERENCES}

1 Zisberg A, Shadmi E, Gur-Yaish N, et al. Hospital-associated functional decline: the role of hospitalization processes beyond individual risk factors. J Am Geriatr Soc 2015;63:55-62.

2 Healthcare Pricing Office. Activity in acute public hospitals in Ireland annual report, 2017. Dublin, 2018.

3 Census 2016 Small Area Population Statistics [Internet], 2016. Available: http://www.cso.ie/en/census/census2016reports/census20 16smallareapopulationstatistics/

4 Blunt I. Focus on preventable admissions: trends in emergency admissions for ambulatory care sensitive conditions, 2001 to 2013. The Nuffield Trust and The Health Foundation, 2013.

5 Tian Y, Dixon A, Gao H. Data Briefing: emergency hospital admissions for ambulatory care-sensitive conditions: identifying the potential for reductions, 2012.

6 Sheridan A, Howell F, Bedford D. Hospitalisations and costs relating to ambulatory care sensitive conditions in Ireland. Ir J Med Sci 2012;181:527-33.

7 Busby J, Purdy S, Hollingworth W. A systematic review of the magnitude and cause of geographic variation in unplanned hospital admission rates and length of stay for ambulatory care sensitive conditions. BMC Health Serv Res 2015;15:324.

8 O'Cathain A, Knowles E, Maheswaran R, et al. A system-wide approach to explaining variation in potentially avoidable emergency admissions: national ecological study. BMJ Qual Saf 2014;23:47-55.
9 Sexton E, Bedford D. GP supply, deprivation and emergency admission to hospital for COPD and diabetes complications in counties across Ireland: an exploratory analysis. Ir J Med Sci 2016;185:453-61.

10 von Elm E, Altman DG, Egger M, et al. The strengthening the reporting of observational studies in epidemiology (STROBE) statement: guidelines for reporting observational studies. PLoS Med 2007;4:e296.

11 Health Service Executive. Primary care reimbursement service: statistical analysis of claims and payments 2016, 2016.

12 The Dartmouth Atlas of Health Care [Internet], 2017. Available: http:// www.dartmouthatlas.org/tools/downloads.aspx

13 Stranges E, Friedman B. Potentially Preventable Hospitalization Rates Declined for Older Adults, 2003-2007: Statistical Brief \#83. Rockville, MD: Agency for Healthcare Research and Quality (US), 2009. https:// www.ncbi.nlm.nih.gov/books/NBK53596/

14 Thygesen LC, Christiansen T, Garcia-Armesto S, et al. Potentially avoidable hospitalizations in five European countries in 2009 and time trends from 2002 to 2009 based on administrative data. Eur J Public Health 2015;25(Suppl 1):35-43.

15 National Patient Safety Office. National healthcare quality reporting system annual report 2018. Dublin, 2019.

16 Ibáñez B, Librero J, Bernal-Delgado $\mathrm{E}$, et al. Is there much variation in variation? Revisiting statistics of small area variation in health services research. BMC Health Serv Res 2009;9:60.

17 McPherson K, Wennberg JE, Hovind OB, et al. Small-area variations in the use of common surgical procedures: an international comparison of New England, England, and Norway. N Engl J Med 1982;307:1310-4.

18 Lynch B, Fitzgerald AP, Corcoran P, et al. Drivers of potentially avoidable emergency admissions in Ireland: an ecological analysis. BMJ Qual Saf 2019;28:bmjqs-2018-008002:438-48.

19 Anselin L, Bera AK, Florax R, et al. Simple diagnostic tests for spatial dependence. Reg Sci Urban Econ 1996;26:77-104.

20 Pisati M. Tools for spatiel data analysis. Stata Technical Bulletin 2001;10.

21 Mobley LR, Root E, Anselin L, et al. Spatial analysis of elderly access to primary care services. Int J Health Geogr 2006;5:19.

22 Barker I, Steventon A, Deeny SR. Association between continuity of care in general practice and hospital admissions for ambulatory care sensitive conditions: cross sectional study of routinely collected, person level data. BMJ 2017;356:j84.

23 Burgdorf F, Sundmacher L. Potentially avoidable hospital admissions in Germany: an analysis of factors influencing rates of ambulatory care sensitive hospitalizations. Dtsch Arztebl Int 2014;111:215-23.

24 Wennberg JE. Time to tackle unwarranted variations in practice. BMJ 2011;342:d1513.

25 Jennings S, Bennett K, Shelley E, et al. Trends in percutaneous coronary intervention and angiography in Ireland, 2004-2011: implications for Ireland and Europe. IJC Heart \& Vessels 2014;4:35-9.

26 Gabet $A$, Juillière $Y$, Lamarche-Vadel $A$, et al. National trends in rate of patients hospitalized for heart failure and heart failure mortality in France, 2000-2012. Eur J Heart Fail 2015;17:583-90.

27 Conrad N, Judge A, Tran J, et al. Temporal trends and patterns in heart failure incidence: a population-based study of 4 million individuals. Lancet 2018;391:572-80.

28 Simmering JE, Tang F, Cavanaugh JE, et al. The increase in hospitalizations for urinary tract infections and the associated costs in the United States, 1998-2011. Open Forum Infect Dis 2017; 4:ofw281.

29 Critchley IA, Cotroneo N, Pucci MJ, et al. The burden of antimicrobial resistance among urinary tract isolates of Escherichia coli in the United States in 2017. PLoS One 2019;14:e0220265.

30 Hodgson K, Deeny SR, Steventon A. Ambulatory care-sensitive conditions: their potential uses and limitations. BMJ Qual Saf 2019;28:429-33.

31 OECD. European Observatory on health systems policies. Ireland: Country Health Profile, 2017.

32 Health Service Executive. Health Service Performance Report: October - December 2016, 2016.

33 Tammes P, Morris RW, Brangan E, et al. Exploring the relationship between general practice characteristics, and attendance at walk-in centres, minor injuries units and EDs in England 2012/2013: a cross-sectional study. Emerg Med J 2016;33:702-8.

34 Wallace E, Smith SM, Fahey T, et al. Reducing emergency admissions through community based interventions. BMJ 2016;352:h6817. 